\title{
PROGRAMA DE PÓS-GRADUAÇÃO EM ENGENHARIA FLORESTAL DA UNIVERSIDADE FEDERAL DO PARANÁ - BRASIL
}

Nivaldo Eduardo Rizzi ${ }^{1}$

\begin{abstract}
RESUMO
Este artigo traça um panorama atual do programa de pós-graduação em Engenharia Florestal da Universidade Federal do Paraná do Brasil. O programa, criado em 1972, está estruturado em cinco áreas de formação: conservação da natureza, economia e política florestal, manejo florestal, silvicultura e tecnologia e utilização de produtos florestais. Estas áreas estão sendo consolidadas por 16 linhas de pesquisa e vários laboratórios acadêmicos. Atualmente atuam no programa 51 doutores titulados por universidades de vários países. O processo de seleção de alunos é anual, tendo atualmente 217 alunos (março 2003). O programa vem evoluindo significativamente nos últimos anos, com vários acordos com instituições nacionais e estrangeiras e produzindo indicadores de produtividade que se expressam mais significativamente no número de titulados, atingindo a marca histórica de 500 titulados (359 mestres e 141 doutores) até o final de 2002 . Cerca de $15 \%$ dos titulados são de países da América Latina.
\end{abstract}

\section{INTRODUÇÃO}

O programa de pós-graduação em Engenharia Florestal da UFPR surgiu em conseqüência da consolidação do curso de graduação e a necessidade de evolução no ensino florestal. Inicialmente o nível de titulação criado foi $o$ de mestrado, posteriormente o doutorado e mais recentemente o pós-doutorado.

O nível de Mestrado em Engenharia Florestal, o primeiro no país nesta modalidade, foi criado em 1972, por iniciativa da Universidade Federal do Paraná e do apoio advindo do Convênio Internacional com a Universidade Albert Ludwig de Freiburg, Alemanha. Foi credenciado pelo Ministério da Educação e Desporto do Brasil em 1976.

O nível de Doutorado, criado em 1982, foi proposto e aprovado pela Universidade Federal do Paraná, após bem sucedida experiência com o Mestrado, tornando-se o primeiro nesta modalidade no Brasil e na América do Sul. Em 1987 o Doutorado foi credenciado pelo Conselho Federal de Educação.

A Universidade Federal do Paraná, no seu dedicado esforço em cumprir sua função de gerar e universalizar conhecimentos para a sociedade, aprovou o programa de PósDoutorado em 1997, como processo de polir recursos humanos, que sejam capazes de conceber novas teorias, comprová-las para consolidar a ciência e inovar tecnologias com a finalidade precípua em disponibilizar a ciência gerada para o consumo da sociedade, melhorando a sua qualidade de vida e protegendo os recursos biosfera.

Atualmente o programa de pósgraduação em Engenharia Florestal titla mestres e doutores nas seguintes Áreas de Concentração: Manejo Florestal (mestrado criado em 1973 e doutorado em 1982), Silvicultura (mestrado criado em 1973 e doutorado em 1982), Economia e Política Florestal (mestrado criado em 1981 e doutorado em 1982), Tecnologia e Utilização de Produtos Florestais (mestrado criado em 1973 e doutorado em 1982) e Conservacãa da Natureza (mestrado e doutorado criado em 1989). A criação desta última área de concentração mostra que o Programa de PósGraduação tem se expandido de forma significativa extrapolando o conceito clássico de área básica de Recursos Florestais e Engenharia Florestal, tendo na atualidade, uma concepção inter e multidisciplinar.

O programa de Pós-Graduação em Engenharia Floresta tem como objetivo ensinar o pós-graduando a ligar o campo teórico ao campo aplicado da Ciência Florestal tendo como base a investigação científica profunda, pormenorizada e dentro de uma especificidade, onde o domínio do setor deve ser considerado ilimitado.

\footnotetext{
${ }^{1}$ Prof. Engenheiro Florestal, Msc. Dr.., Universidade Federal do Paraná, Brasil (www.floresta.ufpr.br/pos-graduacao)
} 
O programa está contribuindo para a formação de professores e pesquisadores para outras Universidades, Institutos de Pesquisa e Empresas, o que lhes confere status pioneiro e consolidados na geração de profissionais qualificados para atuarem no processo de desenvolvimento deste importante segmento da economia nacional.

\section{Inserção na UFPR e administração do programa}

A Universidade Federal do Paraná está estruturada em $10 \quad(\mathrm{dez})$ Setores Administrativos: Setor de Ciências Agrárias (onde se vincula o Programa de PósGraduação), Setor de Ciências Biológicas, Setor de Ciências Sociais Aplicadas, Setor de Educação, Setor de Ciências Humanas, Letras e Artes, Setor de Tecnologia, Setor de Ciências Exatas, Setor de Ciências da Terra e Setor d Tecnologia.

Possui 66 Departamentos, denominadas Unidades Didático-Pedagógicas, onde estão lotados os professores e que ofertam as disciplinas para os cursos de graduação e os programas de pós-graduação. Basicamente os Departamentos que ofertam disciplinas para o Programa de Pós-Graduação em Engenharia Florestal são os seguintes: Departamento de Ciências Florestais (DECIF), Departamento de Engenharia e Tecnologia Florestal (DETF), Departamento de Economia e Extensão Rural (DETER) e Departamento de Engenharia Agrícola e Solos (DEAS), todos eles vinculados ao Setor de Ciências Agrárias da UFPR.

A UFPR atualmente possui 46 programas de pós-graduação (44 mestrados e 26 doutorados). Muito embora estes programas de pós-graduação sejam dependentes dos Departamentos da UFPR, vinculados aos Setores da UFPR, eles respondem diretamente à Pró-Reitoria de Pesquisa e Pós-Graduação (PRPPG) a qual é responsável pela administração do Sistema de Pós-Graduação da UFPR.

A UFPR possui como colegiados superiores: o Conselho de Ensino Pesquisa e Extensão (CEPE) que estabelece a política de didático-pedagógica dos cursos de graduação e pós-graduação; o Conselho de Administração (COPLAD), que estabelece a política da administração; o Conselho Universitário (COUN), como órgão máximo, estabelece a política de planejamento global da instituição (colegiado composto pelos integrantes do CEPE e COPLAD) e o Conselho de Curadores que fiscaliza a administração superior da UFPR.

O programa de pós-graduação é administrado por um Coordenador e Vicecoordenador e tem como fórum consultivo e deliberativo um Colegiado de Programa, com integrantes de representantes de professores e alunos. O pós-doutorado é conduzido por um Colegiado Diretivo.

\section{Qüingentésima sessão de defesa}

Um dos programas de maior produção acadêmica da UFPR, a Pós em Engenharia Florestal promoveu no ano de 2002, 43 defesas, entre teses e dissertações. Iniciando o ano letivo 2003 com 217 alunos, mais do que alguns cursos de graduação, o programa de pós-graduação atualmente possui 51 professores, todos com doutorado.

Como pioneiro, o programa de pósgraduação em Engenharia Florestal da UFPR formou recursos humanos para consolidar a pós-graduação na área em todo o Brasil, participando também da titulação de profissionais de vários outros países. Cerca de $12 \%$ dos egressos são estrangeiros, de países como México, Argentina, Uruguai, Paraguai, Bolívia e Chile, Moçambique, Angola, e, mais recentemente, Alemanha e Japão.

A tabela 1 apresenta estatísticas de titulados até 31 de dezembro de 2002. Mostra que $73,18 \%$ dos Mestres titulados são homens e $26,82 \%$ são mulheres. Titulados Doutores são $75,5 \%$ homens e $24,45 \%$ mulheres. Mostra também que, muito embora a área de Conservação da Natureza tenha sido criada em 1989 , já totaliza $11,03 \%$ dos titulados pelo programa, comprovando a diversificação da ciência florestal nos dias de hoje. 
Tabela 1: Titulados Mestres e Doutores até dezembro de 2002

Table 1: Number of masters and doctors graduated from 1974 a 2002 inclusive

\begin{tabular}{|c|c|c|c|}
\hline \multicolumn{4}{|c|}{ Titulados pelo programa até 31 de dezembro de 2002} \\
\hline \multirow{2}{*}{ Titulados } & Mestrado & Doutorado & \multirow{2}{*}{ Total } \\
\hline & Início em 1973 & Início em 1982 & \\
\hline Homens & $262(73,18 \%)$ & $115(81,56 \%)$ & $377(75,55 \%)$ \\
\hline Mulheres & $96(26,82 \%)$ & $26(18,44 \%)$ & $122(24,45 \%)$ \\
\hline Total & $358(100 \%)$ & $141(100 \%)$ & $499(100 \%)$ \\
\hline Estrangeiros & $41(11,45 \%)$ & $12(8,51 \%)$ & $53(10,62 \%)$ \\
\hline \multicolumn{4}{|l|}{ Áreas de Concentração } \\
\hline Silvicultura & $117(32,68 \%)$ & $53(37,5 \%)$ & $170(34,07 \%)$ \\
\hline Manejo & $98(27,74 \%)$ & $31(21,99 \%)$ & $129(25,85 \%)$ \\
\hline Tecnologia & $58(16,20 \%)$ & $28(19,86 \%)$ & $86(17,23 \%)$ \\
\hline Economia & $45(12,57 \%)$ & $14(9,93 \%)$ & $59(11,82 \%)$ \\
\hline Conservação & $40(11,17 \%)$ & $15(10,64 \%)$ & $55(11,03)$ \\
\hline
\end{tabular}

O primeiro titulado pelo Mestrado em Engenharia Florestal da UFPR, concluiu o curso em 1974, em seguida fez doutorado na Austrália e o pós-doutorado, na Alemanha e atualmente é professor do programa, orientando alunos da UFPR na área de Tecnologia e Utilização de Produtos Florestais.

A dissertação de mestrado de $\mathrm{n}^{0} 500$ é de um pós-graduando com formação em Arquitetura, com o título de "Zoneamento de Áreas de Preservação Permanente e Reserva Legal em Imóveis Rurais Utilizando o SIG". Trata-se de um trabalho de grande aplicabilidade prática, visando a conservação das florestas e água nas propriedades rurais.

\section{Visão geral, evolução e tendências}

Atualmente o curso de pós-graduação possui 51 professores (docentes, pesquisadores ou colaboradores), distribuídos da seguinte forma: área de conservação da natureza (10), área de economia e política florestal (10), área de manejo florestal (10), área de silvicultura (9), área de tecnologia e utilização de produtos florestais (11).

Iniciaram o ano letivo de 2003, 217 alunos (116 de mestrado e 101 de doutorado). No ano de 2002 foram titulados 43 alunos, sendo 20 Mestres e 23 Doutores. Até dezembro de 2002, o programa já produziu 358 Mestres e 141 Doutores. No início de 2003, totalizou 500 sessões de defesas.

A inserção nacional do programa de pós-graduação pode também ser avaliada pelo número de professores de outras instituições (várias universidades brasileiras) que estão se doutorando. Atualmente, o curso possui 17 bolsistas do programa PICDT (Programa Institucional de Capacitação Docente e Técnica do Ministério de Educação).

Os recursos tem sido escassos frente a demanda e a possibilidade de expansão do curso. Grande parte dos recursos das taxas acadêmicas das Agências Nacionais de fomento vem sendo comprometida com a formação de bancas examinadoras de dissertações e teses, já que se entende ser este o mecanismo de integração com a comunidade científica nacional.

Nos últimos anos o programa vem procurando se modernizar em todas as frentes e isto é perfeitamente visível na análise dos indicadores acadêmicos, na modernização de sua gestão, que levam a adotar práticas de planejamento e implementar políticas de investimento em infraestrutura.

O Programa de Pós-Graduação em Engenharia Florestal está localizado geograficamente em região que permite uma relação com vários biomas, refletindo-se na sua estruturação em áreas de conhecimento e na produção diversificada de dissertações e teses (basta verificar os títulos dos trabalhos de conclusão). Localização privilegiada mesmo estando em perímetro urbano, permite interagir freqüentemente com instituições públicas e empresas privadas, possibilitando grande intercâmbio técnico-científico e melhores condições para a execução de trabalhos de pesquisa.

O Programa trabalha com uma estrutura administrativa com grande abrangência de áreas de concentração permitindo a titulação de mestres de doutores 
da distintas áreas de conhecimento. São cinco áreas de concentração (todas com nível de mestrado e doutorado) que bem equivalem a cinco cursos de pós-graduação.

É importante registrar a diversidade da origem da titulação dos professores (países da Europa e EUA), o nível de titulação (8 são professores titulares e 7 tem pós-doutorado) e o tempo de titulação dos professores (superior a 5 anos). Com esta base de massa crítica o programa de pós-graduação consegue formar docentes de outras instituições públicas e privadas e participar na capacitação docente de outras universidades que almejam criar seus cursos de pós-graduação.

$\mathrm{O}$ programa de pós-graduação em Engenharia Florestal é o mais importante da UFPR, pois além de contribuir com a produtividade do sistema de pós-graduação, também projeta a UFPR em âmbito nacional e internacional: em levantamento estatístico de abril de 2002, dos 1245 pós-graduandos de mestrado da UFPR, 95 (7,6\%) são alunos do programa e dos 437 pós-graduandos de doutorado, 102 são alunos do programa $(23,3 \%)$; no ano de 2000 o programa participou com 50,7\% (35) dos titulados doutores (de um total de 69) e 6,2\% (20) de titulados Mestres (de um total de 207).

O programa sempre buscou parceria com instituições nacionais e internacionais que, só não é mais efetiva por dificuldades orçamentárias. Tem convênios com o Centro Nacional de Pesquisa Florestal da Embrapa, Michigan State University, Universidade do Hawai, Universidade da Flórida, Universidade de Cantabria (Espanha), Faculdade Forestal de Missiones da Argentina, Faculdade de Ciências Agrárias do Pará, Universidade de Moçambique (convênio com a UFPR), Instituto Paranaense de Desenvolvimento Econômico e Social do Paraná, Universidade do Contestado, Fundação O BOTICÁRIO.
Oportuno registrar os acordos existentes com as Universidades Federais, tipo o PROCAD com a UFLA e agora, em processo de negociação, o PROCAD com a UFMT. Além destas inserções internacionais registra-se os vários Seminários e Congressos Internacionais organizados por professores cadastrados no Programa e que estão citados nos relatórios anuais DATACAPES.

\section{Indicadores acadêmicos}

A tabela 2 sintetiza dados acadêmicos dos relatórios anuais do sistema de coleta de dados da Agência Nacional, Coordenação de Aperfeiçoamento de Pessoal de Nível Superior (CAPES), por um período de 6 (seis) anos.

Ampliou-se o número de alunos que iniciam o ano letivo, passando de $161(64+24$ de mestrado e 55+18 de doutorado) em 1998 para $198(75+20$ de mestrado e $76+27$ de doutorado) em 2002.

A grande inserção do curso no ambiente técnico se expressa pela simples análise da demanda de ingresso no curso: no período de seis anos (tabela 2) para um total de 297 aprovados, houve um total de 630 inscritos (2,1 candidatos por vaga).

Pode-se qualificar como exemplar a produtividade na titulação de Mestres e Doutores nos últimos 5 anos: foram titulados 93 Mestres e 71 Doutores (somente no ano de 2002 se titularam 20 Mestres e 23 Doutores).

O tempo médio de titulação recomendado pela Agência CAPES (30 meses para mestrado e 48 para doutorado) vem sendo alcançado. Neste período o tempo médio de titulação do mestrado reduziu-se significativamente de 38,1 meses em 1998 para 28,5 meses no ano 2002. Neste mesmo período o tempo médio de titulação para doutorado reduziu-se de 52,1 meses em 1998 para 47,7 meses no ano de 2002 (tabela 2). 
Tabela 2: Indicadores acadêmicos do programa de pós-graduação

Table 2: Academic indicators of the graduate program

\begin{tabular}{|c|c|c|c|c|c|c|}
\hline Ano & 1998 & 1999 & 2000 & 2001 & 2002 & 2003 \\
\hline \multicolumn{7}{|l|}{ MESTRADO } \\
\hline Alunos remanescentes do ano anterior & 64 & 64 & 77 & 64 & 64 & \\
\hline Alunos inscritos no processo de seleção & $(68)$ & $(63)$ & $(57)$ & $(49)$ & $(85)$ & $(68)$ \\
\hline Alunos novos - aprovados pelo processo de seleção & 24 & 27 & 18 & 28 & 36 & 41 \\
\hline Alunos titulados & 15 & 15 & 20 & 23 & 20 & \\
\hline Alunos com abandono ou desligados & 9 & 12 & 11 & 5 & 5 & \\
\hline Alunos no final do ano & 64 & 64 & 64 & 64 & 75 & \\
\hline Alunos bolsistas CAPES & 13 & 14 & 12 & 10 & 11 & 11 \\
\hline Alunos bolsistas CNPq & 12 & 16 & 13 & 13 & 13 & 12 \\
\hline Alunos bolsistas PICDT & 4 & 4 & 0 & 0 & 0 & \\
\hline Média de meses para titulação & 38,1 & 33,6 & 32,2 & 29,2 & 28,5 & \\
\hline \multicolumn{7}{|l|}{ DOUTORADO } \\
\hline Alunos remanescentes do ano anterior & 55 & 63 & 88 & 76 & 76 & \\
\hline Alunos inscritos no processo de seleção & $(39)$ & $(38)$ & $(46)$ & $(35)$ & $(38)$ & $(44)$ \\
\hline Alunos novos - aprovados no processo de seleção & 18 & 25 & 13 & 17 & 27 & 23 \\
\hline Alunos titulados & 7 & 11 & 17 & 13 & 23 & \\
\hline Alunos com abandono ou desligados & 3 & 1 & 4 & 4 & 2 & \\
\hline Alunos no final do ano & 63 & 76 & 76 & 76 & 78 & \\
\hline Alunos bolsistas CAPES & 8 & 9 & 7 & 5 & 7 & 7 \\
\hline Alunos bolsistas CNPq & 12 & 15 & 15 & 13 & 14 & 13 \\
\hline Alunos bolsistas PICDT & 15 & 14 & 12 & 12 & 13 & 15 \\
\hline Média de meses para titulação & 52,1 & $\mathbf{5 2 , 5}$ & 48,7 & 49,2 & 47,7 & \\
\hline \multicolumn{7}{|l|}{ INDICADORES / CORPO DOCENTE } \\
\hline Número total de professores & 47 & 53 & 43 & 45 & 50 & 51 \\
\hline Alunos início do ano (Msc+Dr+Ingressos) / total professores & 3,4 & 3,4 & 4,6 & 4,1 & 4,1 & \\
\hline Alunos final do ano (Msc+Dr) / total professores & 2,7 & 2,6 & 3,3 & 3,1 & 3,1 & \\
\hline
\end{tabular}

A produtividade em termos de titulados tem sido inversamente proporcional ao número de bolsas disponibilizadas pela CAPES e CNPQ, ou seja, mesmo que tenha havido uma redução de bolsas, a resposta é de aumento de número de titulados: o número de bolsas de mestrado da CAPES sofreu um decréscimo de 13 em 1998, para 11 em 2002; o doutorado de 8 em 1998, foi para 7 em 2002; e para 5 em 2001); o CNPQ tem sido mais homogêneo na distribuição de bolsas (atualmente são 13 de mestrado e 14 de doutorado).

Evidencia-se desta maneira que o esforço institucional de ampliação do número de alunos de pós-graduação não é acompanhado do aumento de numero de bolsas concedidas ao curso, obrigando a se ter uma política de relações externas que viabiliza execuções de dissertações e teses. Observa-se que no ano de 1998 o percentual de bolsistas em relação ao número de matriculados foi de $37,3 \%$ (161 matriculados no início do ano para 60 bolsas), em 2002 foi de $28,6 \%$ ( 58 bolsas para 203 alunos).
Há que se destacar que o programa colabora com a capacitação docente do Brasil. Interessante é destacar o número de alunos do Programa Institucional de Capacitação Docente e de Técnicos (PICDT) que estão no curso: a média do período de análise (1998-2003) foi de 13 bolsistas/ano.

Quando se relaciona o número de alunos matriculados por professor, observa-se também que o curso vem atendendo a diretriz da CAPES quanto à produtividade média do professor, mostrando que há uma dedicação acadêmica diferenciada. A média de alunos matriculados (no início do ano base) mantevese sempre acima de três: em 1998 foi de 3,4 alunos/professor e em 2002 foi de 4,1 alunos/professor (tabela 2).

\section{Indicadores de produção técnico-científica}

De maneira semelhante ao tópico anterior, a tabela 3 sintetiza dados de produção intelectual (bibliográfica e técnica) dos relatórios anuais do sistema de coleta de dados (DATACAPES). 
Tabela 3: Indicadores de produção intelectual dos professores

Table 3: Intellectual productions indicators of the graduate professors

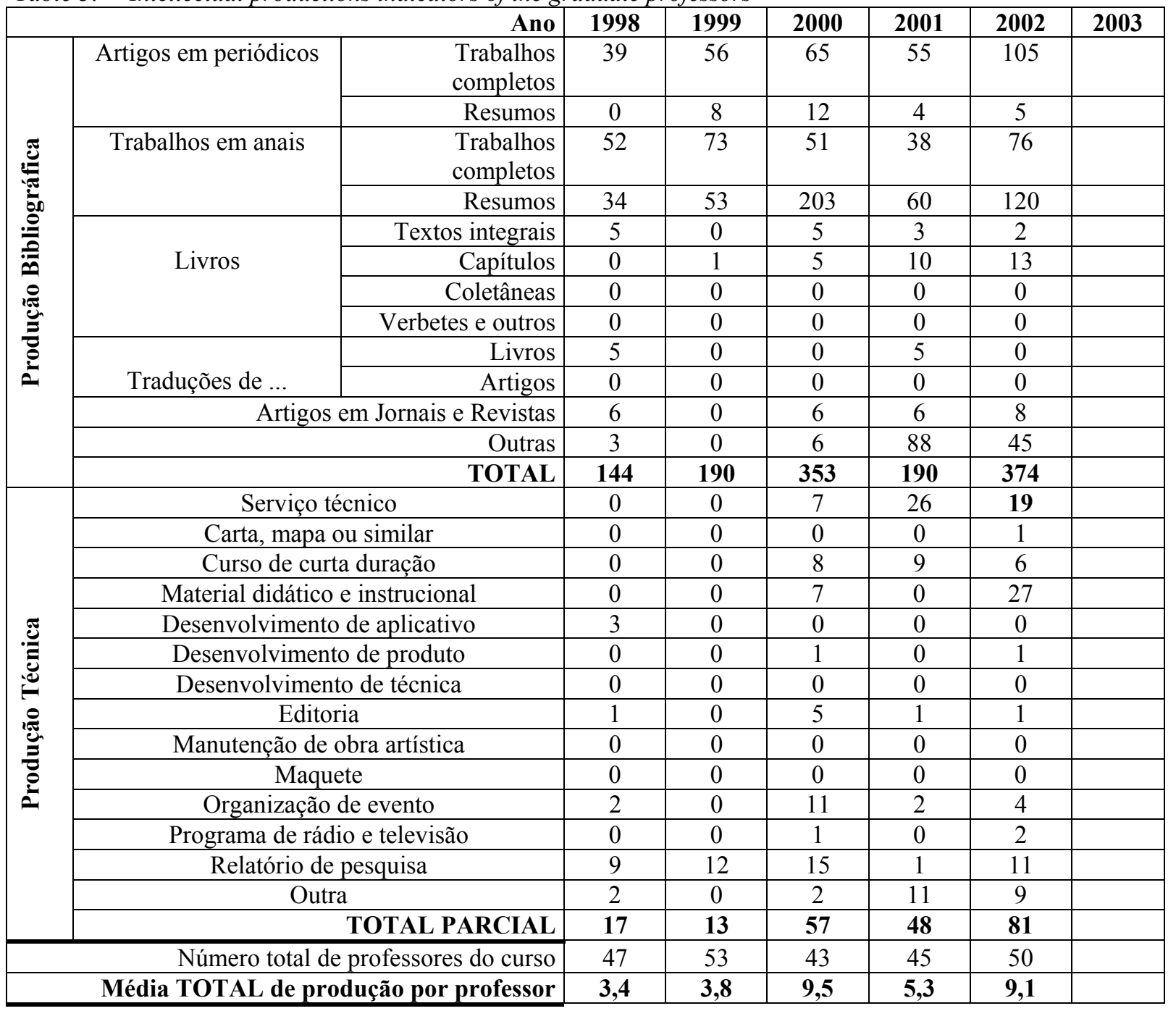

Artigos técnico-científicos por professor

Trabalhos completos como artigos em perIódicos e em anais

$$
\begin{gathered}
\text { Total de artigos } \\
\text { Média por }
\end{gathered}
$$$$
\text { professor }
$$

O grande grupo de produção bibliográfica registrada e classificada pelos relatórios anuais mostra tendência significativa de aumento no período: a média de produção bibliográfica de 1998 foi de 3,4 itens/professor e em 2002 foi de 9,1 itens/professor (tabela 3).

Quando se analisa a produção bibliográfica como artigos e trabalhos completos em periódicos e anais de congressos a tabulação dos dados permite visualizar a evolução da produtividade do programa: 1,9 por professor em 1998 para 3,6 em 1999 (tabela 3).

\begin{tabular}{l|l|l|l|l}
$\mathbf{1 , 9}$ & $\mathbf{2 , 4}$ & $\mathbf{2 , 7}$ & $\mathbf{2 , 1}$ & $\mathbf{3 , 6}$
\end{tabular}

A tabela 3 mostra também valores significativos totalizados: no período de 5 anos (1998 a 2002) o programa produziu 1251 trabalhos de produção bibliográfica e 216 de produção técnica, totalizando 1467 itens de produção intelectual.

\section{Projetos de pesquisa e alunos envolvidos}

A tabela 4 sintetiza dados de projetos de pesquisa dos relatórios INDICADORES do sistema de coleta de dados (DATACAPES) para o período de 1998 a 2002. Verifica-se que houve um crescimento de projetos de pesquisa dos alunos, pois também houve um 
crescimento do número de alunos matriculados. No ano de 1998 foram registrados 95 projetos, de professores e alunos e em 2002 foram 257 projetos.

Tabela 4: Projetos de pesquisa e alunos envolvidos

Table 4: Research projects and evolved students

\begin{tabular}{|c|c|c|c|c|c|c|}
\hline Ano & 1998 & 1999 & 2000 & 2001 & 2002 & 2003 \\
\hline \multicolumn{7}{|c|}{ PROJETOS DE PESQUISA REGISTRADOS } \\
\hline Em andamento & 94 & 35 & 150 & 208 & 213 & \\
\hline Projetos concluídos & 1 & 15 & 36 & 55 & 44 & \\
\hline Projetos vinculados as linhas de pesquisa & 95 & 50 & 186 & 263 & 257 & \\
\hline Projetos financiados & 18 & 13 & 97 & 97 & 100 & \\
\hline Projetos sem financiadores & 77 & 37 & 89 & 167 & 157 & \\
\hline Projetos com financiamento de bolsas & 11 & 12 & 97 & 97 & 100 & \\
\hline Total de projetos & 95 & 50 & 186 & 264 & 257 & \\
\hline
\end{tabular}

\section{ALUNOS ENVOLVIDOS}

\begin{tabular}{|c|c|c|c|c|c|}
\hline Alunos de graduação & 157 & 53 & 85 & 208 & 226 \\
\hline Alunos de especialização & 19 & 15 & 11 & 31 & 0 \\
\hline Alunos de mestrado & 164 & 40 & 111 & 96 & 101 \\
\hline Alunos de doutorado & 160 & 34 & 43 & 133 & 129 \\
\hline Total de alunos envolvidos & 500 & 142 & 350 & 468 & 456 \\
\hline
\end{tabular}

INDICADORES POR PROFESSOR

\begin{tabular}{|c|c|c|c|c|c|c|}
\hline Número total de professores do curso & 47 & 53 & 43 & 45 & 50 & 51 \\
\hline Média de projetos de pesquisa por professor & 2,02 & 0,94 & 4,33 & 5,9 & 5,1 & \\
\hline Total de alunos envolvidos por professor & 10,7 & 2,74 & 8,14 & 10,4 & 5,1 & \\
\hline
\end{tabular}

Observa-se de outra maneira que o curso de pós-graduação mantém historicamente alta percentagem de projetos que não tem financiamento, isto é, são executados com recursos próprios dos alunos muitas vezes pela concessão de bolsa, ou com apoio de empresas ou instituições públicas (material, dados, etc). Este é um mérito dos pós-graduandos e do bom e histórico relacionamento do curso de pós-graduação com as instituições públicas e as empresas florestais. Observa-se que em 1998 do total de projetos registrados $81,1 \%$ (77 de um total de 95) não possuíam qualquer tipo de financiamento. Em 2002 este percentual diminuiu para $61,1 \%$ (157 de um total de 257 ).

Evidencia-se nesta tabela que há uma grande participação de alunos de graduação nos projetos de pesquisa. Em 1998 dos 500 alunos envolvidos na execução dos projetos de pesquisa 31,4\% (157 alunos) eram alunos de graduação e em 2002 foi de 49,6\% (226 alunos) e em 2000 este percentual foi de $31,3 \%$.

Os registros destes dados permitem afirmar que a média de projetos de pesquisa com participação mais efetiva dos professores tem aumentado, pois além de ser obrigado pela instituição a executar projeto de pesquisa próprio, também está relacionado ao projeto de seu orientado.

Em virtude dos professores do Programa atenderem cursos de graduação no âmbito da Universidade, há excelente integração entre ambos, principalmente com o envolvimento de alunos da Graduação na dinâmica do ensino de pós-graduação sendo significativo o envolvimento com as pesquisas de tese/dissertações. A integração também é realizada através das linhas de pesquisa do professor que tem se utilizado de bolsistas do PIBIC/CNPQ, PET e Fundação de Pesquisas da UFPR - FUNPAR.

O Evento de Iniciação Científica da UFPR é conceituado nacionalmente e tem grande participação dos professores que atuam no curso. Em sua nona edição, ampliando a sua abrangência, a UFPR estabeleceu normas para participação de alunos de pós-graduação no evento o que poderá trazer ainda maiores benefícios de integração graduação/pósgraduação.

Também contribui para esta integração a execução de pesquisas seja através do apoio do CNPQ (Produtividade em Pesquisa - 13 professores), seja através da Fundação de Pesquisas Florestais do Paraná - FUPEF.

Esta integração ainda necessita de maior avanço de mecanismos mais formais e 
as estratégias já começaram a ser discutidas no âmbito da Universidade através de encontros e seminários realizados durante $\mathrm{o}$ ano que passou. Um exemplo deste avanço na integração entre graduação e pós-graduação é a implementação da Cooperativa de Alunos denominada Consultoria de Planejamento Florestal (COPLAF) que vem desenvolvendo inúmeros trabalhos de consultoria sob orientação dos professores com atuação no Centro de Ciências Florestais e da Madeira.

\section{Infraestrutura de laboratórios}

De maneira geral os laboratórios do Programa necessitam de melhorias no sentido de modernizá-los no que diz respeito à equipamentos já que desde abril de 2000 o programa está instalado em nova sede no Campus do Jardim Botânico, denominado Centro de Ciências Florestais e da Madeira, aproximadamente $50.000 \mathrm{~m} 2$, com área construída de $10.000 \mathrm{~m} 2$ (bloco I e bloco 2 de tecnologia). Os laboratórios existentes são os seguintes: paisagismo e áreas silvestres, fauna, incêndios florestais, manejo de bacias e qualidade de água, dendrologia e herbário, planejamento e administração florestal, dendrometria, inventário florestal, computação e informática, manejo florestal, geoprocessamento, fotointerpretação, ciência do trabalho e colheita da madeira, silvicultura, áreas degradadas, proteção florestal, colheita da madeira e oficinas, arboricultura e melhoramento florestal, fisiologia, ecologia, sementes, segurança do trabalho e exploração florestal, anatomia da madeira, biodegradação da madeira, química da madeira, polpa e papel, beneficiamento da madeira, energia da biomassa florestal, painéis de madeira, preservação da madeira, tecnologia da madeira, usinagem.

O programa de pós-graduação conta com um laboratório de Informática, que serve também aos alunos de graduação dos cursos de Engenharia Florestal e Engenharia Industrial Madeireira, e praticamente todos os professores possuem computador de uso pessoal em seus gabinetes. Estes computadores são geralmente de última geração e estão ligados à rede Internet. Esta tem sido uma das maiores preocupações das gestões do curso de pós-graduação.
A exemplo de 1998, durante o ano de 1999 a atualização do acervo da biblioteca que estava se processando nos anos anteriores sofreu uma interrupção devido à falta de recursos. Esta atualização até 1997 foi financiada com um percentual equivalente à $10 \%$ das taxas acadêmicas provenientes da CAPES.

A biblioteca do Setor de Ciências Agrárias onde está situado o acervo bibliográfico de Engenharia Florestal foi reestruturada neste ano de 2000. Com esta reestruturação o acervo de aproximadamente 8000 títulos foi transferido para o Centro de Ciências Florestais e da Madeira, onde está localizado o curso de pós-graduação.

\section{Atividades complementares e intercâmbios institucionais}

Vários professores do programa se destacam em participações complementares, com freqüentes convites para participar em bancas examinadoras (teses, dissertações, concursos para o magistério superior), conferências, consultorias científicas, entre outras. Esta participação tem sido através da implementação de projetos de pesquisa e desenvolvimento, bem como da organização de simpósios e congressos para atender demandas de instituições públicas e privadas. Estas atividades são realizadas geralmente através da Fundação de Pesquisas Florestais - FUPEF.

Tem havido continuidade na realização do evento "Seminários da Pós-Graduação" de iniciativa da representação discente e apoiado pela Coordenação do Programa. Este evento objetiva discutir a Pós-Graduação em Engenharia Florestal no âmbito da UFPR através de palestras seguidas de debates com vários outros coordenadores de programas $\mathrm{e}$ autoridades da Pró-Reitoria. O evento também elegeu temas de interesse técnico-científico para os quais são convidados conferencistas de renome.

A Revista Floresta órgão de divulgação cientifica da Fundação de Pesquisas Florestais do Paraná, foi durante o ano de 2002 totalmente reformulada, quanto ao seu formato e Conselho Editorial.

O curso sempre buscou parceria com instituições nacionais e internacionais que, só não é mais efetiva por dificuldades 
orçamentárias. Tem convênios com o Centro Nacional de Pesquisa Florestal da Embrapa, Michigan State University, Universidade do Hawai, Universidade da Flórida, Universidade de Cantabria (Espanha), Faculdade Florestal de Missiones da Argentina, Faculdade de Ciências Agrárias do Pará, Universidade de Moçambique (convênio com a UFPR), Instituto Paranaense de Desenvolvimento Econômico e Social do Paraná, Universidade do Contestado, Fundação O BOTICÁRIO.

Também é oportuno registrar que muitos programas de intercâmbio institucional ocorrem na UFPR, nos Departamentos onde estão lotados os professores e que, por extensão, tem relação com o curso de pósgraduação. Cita-se o PROCAD do Departamento de Engenharia e Tecnologia Florestal com a Universidade de Lavras e a renovação do convênio com a Universidade de FRIBURG (Alemanha) que vem sendo conduzido pelo Departamento de Ciências Florestais.

Programa também tem estado presente junto ao Conselho de Desenvolvimento Florestal Sustentado do Mercosul CEDEFOR/MERCOSUL tendo representantes nas seguintes comissões: Universidades; Treinamento; Política Florestal; Qualidade de Produtos Florestais.

\section{Linhas de pesquisa}

Com o propósito de consolidar estas linhas através da oferta de disciplinas adequadas e cadastro de professores, a Coordenação do programa promoveu uma completa reestruturação curricular no transcurso do ano de 2001. As linhas de pesquisa do curso de pós-graduação estão vinculadas às áreas de concentração: conservação da natureza (5), economia e política florestal (3), manejo florestal (3), silvicultura (2) e tecnologia e utilização de produtos florestais (3). A seguir se lista as linhas de pesquisa.

- Conservação e planejamento integrado de bacias e de recursos hídricos.

- Ecologia e conservação de ecossistemas vegetais.

- Áreas verdes, arborização urbana e estudo de paisagem.

- Unidades de Conservação e Biodiversidade.

- Ecologia, controle e uso do fogo.

- Economia e política de produtos e de mercados florestais.

- Economia do meio ambiente e de produtos não madeiráveis.

- Administração, marketing e estratégia florestal.

- Processamento de imagens e sistemas de informações espaciais aplicadas aos recursos naturais.

- Inventário florestal, sistemas e métodos de amostragem.

- Manejo de florestas e de povoamentos florestais.

- Silvicultura e melhoramento de espécies florestais.

- Produção, abastecimento, proteção e recuperação florestal.

- Tecnologias de exploração, caracterização e uso de madeiras e de produtos da madeira.

- Processos de transformação e controle industrial da madeira e de produtos da madeira.

- Gestão da qualidade e otimização de processos de industrias florestais. 
Foto 1: Vista do Centro de Ciências Florestais e da Madeira

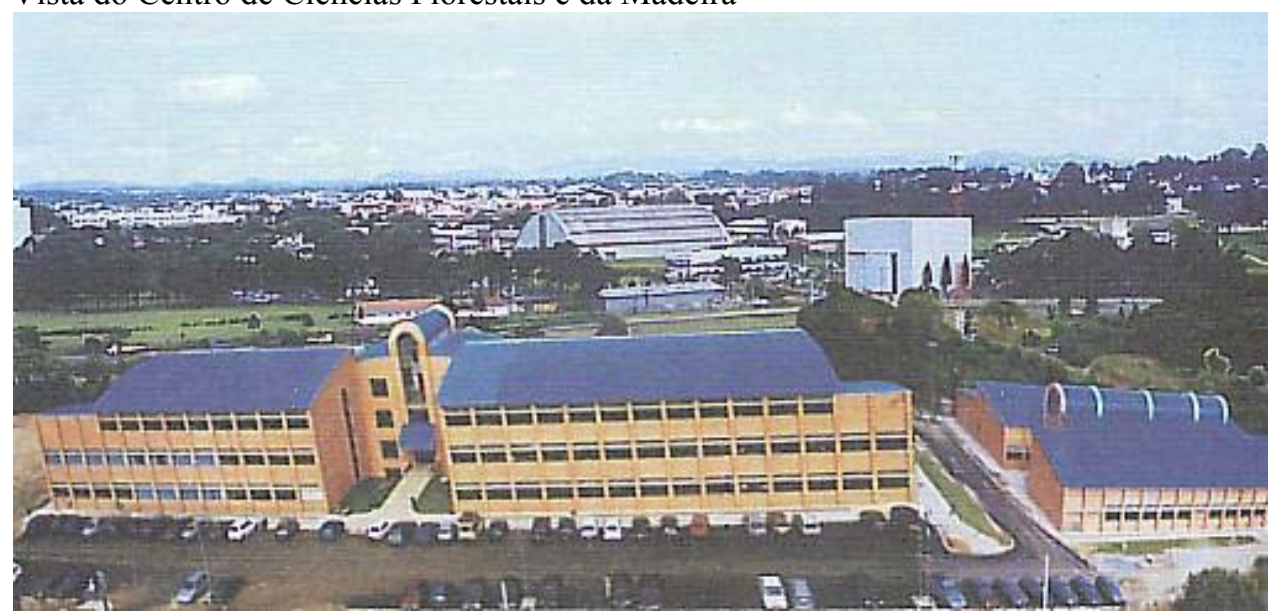

Foto 2: Vista dos fundos do Centro de Ciências Florestais e da Madeira

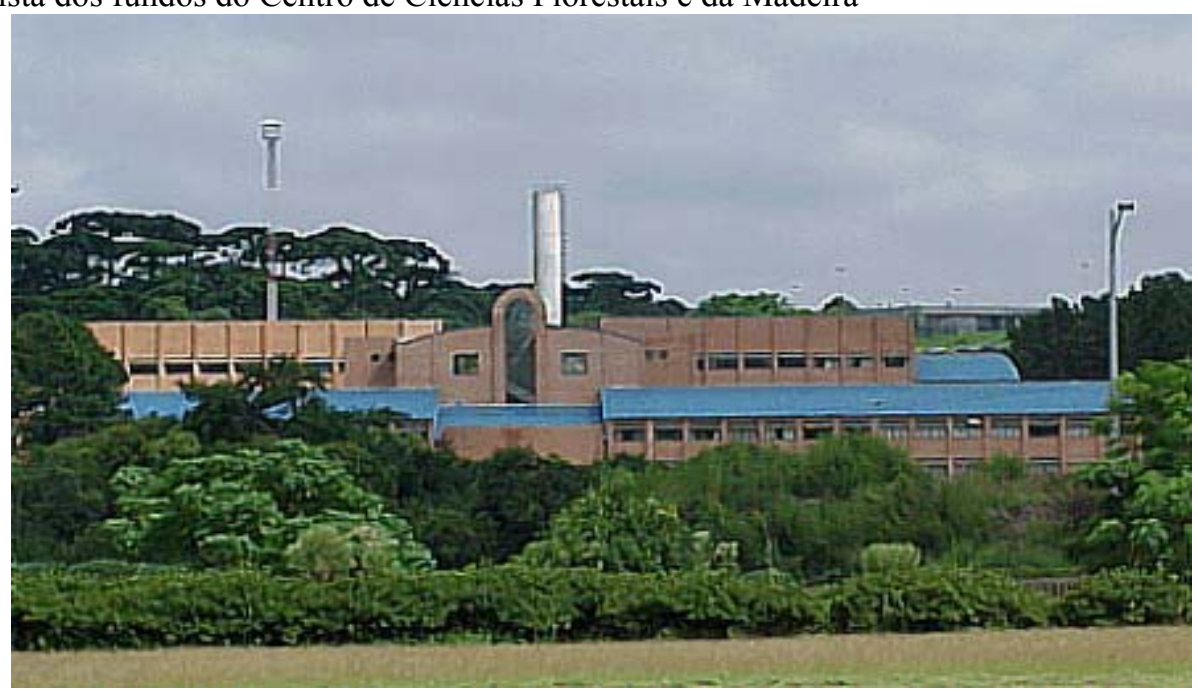

Foto 3: Entrada do Centro de Ciências Florestais e da Madeira

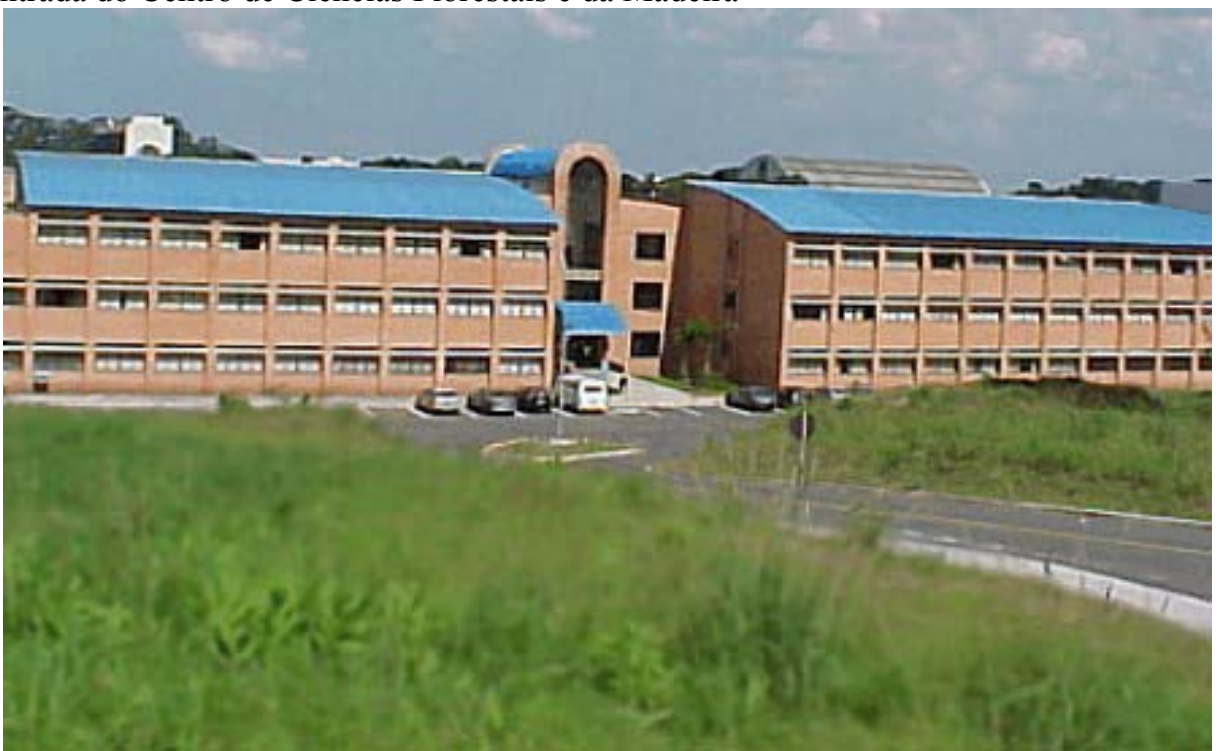

